\title{
The present situation and Prospect of sports industry in Colleges and
}

\author{
Universities \\ Weiwei Liu \\ Jiangxi Institute of Economic Administrators,Jiangxi,Nanchang,330088
}

Key words: college,sports, industry,development, present,situation.

\begin{abstract}
: the analysis based on product characteristics and market demand, the management strategy of sports industry in Colleges and universities from the college sports venues, colleges and universities competition, the high level sports team and sports teachers in Colleges and universities four aspects were discussed, so that colleges and universities can be combined with the actual situation of the school to develop business strategy with characteristics of the university sports industry market.
\end{abstract}

Sports industry is a new type of management system and operational mechanism, which is adapted to the social and economic system reform, to the market, and to promote the development of sports industry. Under the condition of socialist market economy, China's athletic sports and mass sports industry more and more deep, and school physical education is one of the three pillars of sports, in the formation of the road of industrialization started late, development is relatively backward. School physical education is the need to keep its rightful place and sustainable development, take the road of industrialization, many raise funds for school sport injected vigor and vitality is to keep the new concept of the survival and development, is the "sunrise industry" in the sports industry. To develop sports industry, it is necessary to conform to the social sports, industrialization operation rules, in the specific operation of the project and the management way, still need to differences in social sports industry. Each school have their actual situation and professional quality, industrial projects must embody and play the advantage, according to the characteristics of the resources, through appropriate management, actively develop the relevant market, formed distinctive school sports industry. Colleges and universities have a variety of sports resources. The development and use of these resources, in addition to meet the needs of teaching and exercise, but also to serve the community.

\section{The resources of sports industry in Colleges and universities in China and the development of the status quo}

Since 1995 the country puts forward the sports should "take the process of socialization, industrialization road", the development of sports industry in China emerged gratifying scene, which forms the subject of a series of sports industry development pattern to fitness and entertainment industry, competition performance industry. At the same time, college sports also unwilling to remain out of the limelight, in the search for physical education reform in Colleges and universities at the same time, many scholars will sights on foreign colleges and universities sports industry development model, such as the United States, and, trying to make college sports in China also took to the road of sports industry development. However, different colleges and universities in the market, as an important part of higher education, it bears the mission of education and cultivation objectives and management system in Colleges and universities determines the 
development of sports industry in higher education is bound to face many difficulties.

In market economy gradually mature today, colleges and universities use their own resources and awareness in the development of the sports industry has also been enhanced, got rid of the original planned economy system and the social status of "zero contact", part of the colleges and universities began to try for the school sports resources in teaching and industrial development with the grasping simultaneously, the optimal allocation. Some colleges and universities have found an effective way to make full use of the sports resources of our school. Survey shows that the development and utilization of sports resources in Colleges and universities is still not optimistic, mainly from the following aspects to show its deficiencies:

\section{Management of stadiums and stadiums}

The management form and utilization rate of sports stadiums reflect the management level of the sports industry of the school. According to the survey, $48.6 \%$ of the university sports venues open to the public, $42.9 \%$ and a half open, not open to the public only accounted for $11.9 \%$. Visible, China's university sports stadiums also gradually adapt to the needs of social development and national fitness, for the community, from the original single teaching function to the operation of the multi functional direction change. The sports venues in Colleges and universities are the necessary places for the teaching of physical education and extracurricular sports activities. Then, whether the stadium to the community will affect the normal physical education and extracurricular exercise, the answer has no influence on the $33.3 \%$, the impact of the $61.9 \%$. But $45.2 \%$ of the schools that "although the impact, after efforts to this contradiction can be adjusted". These phenomena are the serious waste of college sports industry resources.

The sports venues and facilities of the first to in meet the school teaching, training tasks under the premise, considering fully open to the public, with our fitness of the Dongfeng, increase to community residents near the school publicity and openness, the schools and the community fitness activities to mix well. Develop detailed management rules, appoint someone to be responsible for management, to make clear the venues and facilities of the "responsibility", "right", "Lee", the school has the ownership, management and use rights owned by the sports industry sector.

\section{The sports club operation}

According to the survey, the Japanese MITI, sports club in the form of $66.7 \%$ operation by membership, combined with the membership and temporary customer accounted for $21.57 \%$, completely casual customer system accounted for 3.92\%. From the proceeds of these three forms of operation, the use of membership of the sports club about $80 \%$ is profitable. There are about $70 \%$ of the sports clubs that are profitable for the membership and temporary customers. And a total of $100 \%$ temporary customer system of sports clubs. According to our survey in the open and semi open stadium, in the form of membership management accounted for $7.1 \%$; membership and temporary customer system, the combination of the most, for $47.8 \%$. But it still accounts for $23.8 \%$ of the total temporary customer system. It can be seen that there is still a considerable part of the management of the sports industry in our country at the stage of primitive management level.

\section{The sports}

Influenced by the development of the sports industry in domestic, have been walking in front of other colleges and universities sports industry of our country universities athletics market operation, Philips Football League, CUBA basketball league tournament has affected nationwide, but these big events, and can not assurance school profit, for some schools, some small events, such as some traditional campus events or school hosted some provincial and municipal competitions, it may bring economic benefits. Each school has some traditional events, such as the school's track and field sports will, these games almost and the school has a same long history, it to the school each a 
students have great influence, and the large number of participants. So this event also has a certain market demand and commercial value.

\section{The sporting goods business}

Sports goods consumer market is the sports of all kinds of people on the premise of sports consumption, while the production of sporting goods standards, specifications and use of the functional requirements of sports items as required. Therefore, sports goods is an important part of the total system of sports market. Schools engaged in sporting goods market activities in the scope of 3 areas: Sports uniforms, swimming clothes and other appliances, sports equipment, etc.. Sports goods, equipment, equipment sales and business accounted for 52.4\%; sports wear, sports shoes sales and business accounted for $47.6 \%$, also accounted for a higher proportion. Therefore, colleges and universities have a large number of students, teachers, they are the main and fixed group of these consumption.

\section{The high level sports team management}

Universities have a high level of sports team, can provide the product is a game of some projects, performances, and so on, the market needs to be developed in the potential market demand. In the operation of its market, should actively seek cooperation or sponsorship, of course, to be based on mutually beneficial cooperation between the two sides. Cooperation between college and enterprise joint office team, enterprises can with the help of college sports teams to stimulate the development of enterprise sports activities, to enrich the cultural life of enterprise staff's sports, improve the body quality of the staff and workers of the enterprise, and to improve the health level, so as to improve the production efficiency of enterprises and reduce the employee's medical expenses; can also through some games, promote the enterprise's brand image. In addition, the high level of team members can also participate in some enterprises to participate in competitions between enterprises, but also to help train the sports team.

In its market operation, key points and is seeking with the potential market demand of businesses or business, this kind of enterprise should be some of the benefits of good for large and medium-sized enterprises, has a good tradition of sports, and regularly carry out some sport activities, of course, in geographical location, preferably near the school, cooperative office team details must be decided according to the specific conditions of the local.

University sports industry should continue to adhere to the national fitness as the main purpose, to play the advantages of university personnel and facilities, and gradually move towards the above 5 directions. The relevant leaders of colleges and universities give certain preferential policies to the management, and lower the management power, establish the management system to adapt to the market economy, so as to ensure the healthy development of the sports industry in Colleges and universities. Conditions of colleges and universities but also with social enterprises linked, to provide enterprises with the development of science and technology talent, knowledge structure and other intangible assets, attract or with the aid of enterprise funds, equipment and other tangible assets, joint development of the sports equipment, supplies, health foods, such as market, to solve the shortage of sports industry shortage of funds.

\section{Summary}

With the deepening and development of market economy, the development trend of higher education system has become inevitable. Colleges and universities still have the advantages of various resources, such as the lack of use of resources, poor market economy and so on. To this end, the higher learning institutions in the teaching tasks can be successfully completed at the same time, we should increase the intensity of reform, open the gate, as soon as possible to complete the 
socialist market economic system. Colleges and universities have a large number of sports venues, the venues and facilities, with a variety of excellent sports talents and other professional talents, has the strong humanities environment, institutions of higher learning all kinds of resources should be integrated, to carry out a wide range of all kinds of sports industry projects. Universities should give full play to their own advantages, in order to raise the body, so that their use of a variety of advantages closely combined with other units, to raise funds for the country's sports industry and the cause of national fitness to make due contributions.

\section{Reference:}

[1] Ge Bing song king Yong Fu: the factors affecting the development of sports industry analysis [J]. Journal of Jilin Institute of Physical Education, 2004, (04)

[2] the Huang Xiao Hua Xu Huiling: re understanding of the fundamental problems of the western development of sports industrialization in [J]. Journal of physical education, 2002, 9 (4): 17 19

[3] Zhou Xiaogang: look at the prospect of China's sports industry [J]. economist from foreign sports industry, 2002 (5): 264

[4] Bai li Liu Zhang Yan: sports competitions in China market development situation and existing problems [J]. Journal of Chengdu Institute of physical education, 1999, 25 (4): 3 to 6

[5] history: Shaanxi Bingwang Ming Xian sports industry development system and Study on the concept of [J]. sports culture Herald, 2003 (2): $5 \sim 7$

[6] Qu Shibo: college sports industry have a brilliant future [N]. market report, 2002

[7] Zhang Yan: the connotation and constitution of sports market [J]. Journal of Beijing Institute of Physical Education Teachers College, 1999, 11 (4): 5 12

[8] Zhou Minghua: the development of market economy and sports industry in China [J]. Journal of physical education, 2003,10 (4): $15 \sim 17$

[9] He Zhi Lin Gong Xian: Shanghai sports competition market present situation and countermeasures [J]. Journal of Shanghai Physical Education Institute, 1999,23 (4): 20 to 25

[10] Zeng Ming Guo Cengcheng: the present situation and development of sports industry in Colleges and universities in China [J]. Hubei sports science and technology

[11] Wang Zhiling: analysis of the current college sports industry social responsibility [J]. Journal of Nanjing Sport Institute (SOCIAL SCIENCE EDITION), 2007,05

[12] Yang Wenxuan: for the twenty-first Century [N]. China university sports education, 2001

[13] Hirose Ichiro: [J].RIET electronic information, 2004 (11), the misunderstanding of the reform of the professional sports industry in Japan

[14] Ge Xiaojuan: the development characteristics of international sports industry and the strategy of China [J]. Journal of physical education, 2002 (8)

[15] Shi Peihua: to create a better macroeconomic policy environment for the development of sports industry [M]. speech at the world sports forum, 2005:24 